\title{
The effect of polyunsaturated fatty acids, including conjugated linoleic acid, on calcium absorption and bone metabolism and composition in young growing rats
}

\author{
Owen Kelly ${ }^{1}$, Siobhan Cusack ${ }^{1}$, Christopher Jewell ${ }^{1}$ and Kevin D. Cashman ${ }^{1,2^{*}}$ \\ ${ }^{1}$ Department of Food and Nutritional Sciences and \\ ${ }^{2}$ Department of Medicine, University College, Cork, Republic of Ireland
}

(Received 14 October 2002 - Revised 13 May 2003 - Accepted 2 June 2003)

The effect of polyunsaturated fatty acids (PUFA), in particular conjugated linoleic acid (CLA), on Ca and bone metabolism is unclear. In a $2 \times 2$ factorial design study, forty male 4-week-old rats were fed a control diet containing $70 \mathrm{~g}$ added fat (soyabean oil (SBO; $n$-6 PUFArich diet) or menhaden oil-safflower oil (MSO; $n$-3 PUFA-rich diet))/kg diet with 0 or $10 \mathrm{~g}$ CLA $/ \mathrm{kg}$ for 8 weeks. Ex vivo prostaglandin $\mathrm{E}_{2}$ biosynthesis by bone organ culture was significantly higher $(P<0.001)$ in rats consuming SBO compared with MSO, irrespective of CLA. Addition of the CLA treatment to either diet further lowered $(P<0 \cdot 05)$ ex vivo prostaglandin $\mathrm{E}_{2}$ production. Neither PUFA type nor CLA altered circulating or femoral mRNA levels of osteocalcin (a marker of bone formation) or insulin-like growth factor-I (a mediator of bone metabolism). While urinary pyridinium crosslinks levels (markers of bone resorption) were unaffected by CLA irrespective of PUFA type, they were significantly higher $(P<0.05)$ in rats consuming SBO compared with MSO irrespective of CLA. Net fractional $(\%)$ and absolute (mg) Ca absorption were significantly $(P<0.01$ and $P<0.05$ respectively) higher in CLA-supplemented than unsupplemented animals fed on the $n$-3 PUFA-rich diet, whereas CLA had no effect in animals fed the $n$-6 PUFA-rich diet. There was no effect of CLA supplementation on bone mineral mass. In conclusion, CLA supplementation over 8 weeks appeared to enhance Ca absorption in young growing rats fed an $n$-3 PUFA-rich diet, but had no measurable effect on bone metabolism or bone mass over this time frame.

Calcium absorption: Bone metabolism: Conjugated linoleic acid: Polyunsaturated fatty acid

While dietary factors, such as $\mathrm{Ca}, \mathrm{Mg}, \mathrm{Na}, \mathrm{Cu}$, non-digestible oligosaccharides and vitamins $\mathrm{D}$ and $\mathrm{K}$, amongst others, have attracted considerable attention (Cashman, 2002), the influence of dietary lipids on $\mathrm{Ca}$ metabolism and bone health has received much less research emphasis (Kruger \& Horrobin, 1997). There are some animal data to suggest that supplementation of the diet with $\gamma$-linoleic acid (18:3n-6)-eicosapentaenoic acid (20:5n-3) (3:1, w/w) may promote intestinal $\mathrm{Ca}$ absorption, $\mathrm{Ca}$ balance and bone $\mathrm{Ca}$ content as well as reducing urinary pyridinoline excretion (marker of bone resorption) in experimental rats, relative to control animals supplemented with linoleic acid $(18: 2 n-6)-\alpha$-linolenic acid $(18: 3 n-3)(3: 1$, w/w $)$ (Claassen et al. 1995a,b). These benefits to $\mathrm{Ca}$ absorption and bone were not evident in the lower $\gamma$-linoleic acid:eicosapentaenoic acid ratio groups (Claassen et al. $1995 b)$, suggesting the $n-6: n-3$ fatty acid ratio may be important. These observations have been supported by the results of a controlled pilot study in elderly women (mean age 79.5 years) with senile osteoporosis: these suggest that $\gamma$-linoleic acid and eicosapentaenoic acid (together with $\mathrm{Ca}$ ) have beneficial effects on bone turnover as well as on the bone mineral density of the lumbar spine and femur (Kruger et al. 1998). On the other hand, van Dokkum et al. (1983) showed that increasing the linoleic acid level in the diet of young men participating in a mineral balance study significantly reduced faecal $\mathrm{Ca}$, indicating stimulation of $\mathrm{Ca}$ absorption by $n-6$ essential fatty acids. Therefore, the effects of different bioactive fatty acids on $\mathrm{Ca}$ and bone metabolism, as well as their mechanisms of action, are unclear.

While much of the attention over the last 5 years has focused on the possible beneficial affects of conjugated linoleic acid (CLA), another potentially bioactive polyunsaturated fatty acid (PUFA), on body composition, lipoprotein metabolism, inflammation and carcinogenesis (for reviews, see Kritchevsky, 2000; Roche et al. 2001a), recently attention has focused on a possible beneficial effect of CLA on Ca absorption and bone health. Park et al. (1997) have reported that dietary supplementation

\footnotetext{
Abbreviations: CLA, conjugated linoleic acid; GAPDH, glyceraldehyde phosphate dehydrogenase; IGF, insulin-like growth factor; MSO, menhaden oil-safflower oil; PG, prostaglandin; PUFA, polyunsaturated fatty acid; SBO, soyabean oil.

* Corresponding author: Professor Kevin D. Cashman, fax + 35321 4270244, email k.cashman@ucc.ie
} 
with CLA in experimental mice led to a reduction in whole-body fat and an increase in body protein, water and ash; the increase in whole-body ash content suggests that CLA may enhance bone mineralization and protect against bone loss. This contention was supported by the finding that bone ash was higher in the tibia of CLA-fed chicks compared with control animals (Cook et al. 1997). The mechanism by which CLA may increase bone ash is unclear. Watkins et al. (1997) found that a dietary source of anhydrous butterfat (a rich natural source of CLA) stimulated the rate of bone formation in young growing chicks by modulating prostaglandin $(\mathrm{PG}) \mathrm{E}_{2}$ production in bone. $\mathrm{PGE}_{2}$ plays an important role in the local regulation of bone formation and bone resorption (Marks \& Miller, 1993). However, Li et al. (1999) recently reported that dietary CLA ( $10 \mathrm{~g} / \mathrm{kg}$ diet for 8 weeks) actually led to lowered ex vivo $\mathrm{PGE}_{2}$ production in bone organ culture from young growing rats fed a diet high in either $n-3$ or $n-6$ PUFA. This decreased $\mathrm{PGE}_{2}$ biosynthesis may have led to the reduced rates of mineral deposition and bone formation in CLA-supplemented rats, even though bone mass and mineral content were unaffected by CLA supplementation. $n$-3 PUFA also lowered ex vivo $\mathrm{PGE}_{2}$ production compared with n-6 PUFA, an effect independent of CLA (Li et al. 1999). There may also be situations where CLA and $n-3$ and/or $n$-6 PUFA interact. For example, Li et al. (1999) found that CLA supplementation increased serum levels of a particular binding protein for insulinlike growth factor (IGF)-I (a mediator of bone metabolism), namely IGF-binding protein-3, in rats given a diet high in $n-6$ PUFA, but decreased it in rats fed a diet high in $n$-3 PUFA.

Recent research using the Caco- 2 cell model (a useful in vitro model for predicting $\mathrm{Ca}$ absorption in human subjects; Fleet \& Wood, 1999) also suggests that chronic (2-3-week) exposure of these cells to specific isomers of CLA can stimulate paracellular Ca transport (Jewell \& Cashman, 2003a,b). In this way, therefore, CLA may indirectly influence bone mass by making more $\mathrm{Ca}$ available for calcification. However, to date, there has been no study of the effect of CLA on Ca absorption in vivo.

Therefore, the objective of the present study was to investigate the effect of PUFA type (n-3 v. n-6), CLA, and their possible interactions, on $\mathrm{Ca}$ absorption, bone metabolism (i.e. bone formation and bone resorption) and bone composition in young growing rats.

\section{Materials and methods}

\section{Preparation of rat diets}

The basal diet (AIN-93G (Reeves et al. 1993) without fat) contained one of the following lipid treatments: soyabean oil (a diet rich in $n$-6 PUFA; SBO) or menhaden oil-safflower oil (56:44 (w/w), a diet rich in $n-3$ PUFA; MSO) at $70 \mathrm{~g} / \mathrm{kg}$ diet with or without added CLA (Table 1). For diets containing CLA (SBO+CLA and MSO+CLA), $10 \mathrm{~g}$ dietary $\mathrm{SBO}$ or $\mathrm{MSO} / \mathrm{kg}$ respectively were replaced with CLA (generously provided by Loders Croklaan B.V., Wormerveer, Holland). The SBO diet (AIN-93G) also served as a control diet since it contained all known
Table 1. Composition of the modified AIN-93G diet*

\begin{tabular}{lr}
\hline Ingredient & $\begin{array}{r}\text { Content } \\
(\mathrm{g} / \mathrm{kg})\end{array}$ \\
\hline Casein & 200.000 \\
L-Cystine & 3.000 \\
Maize starch & 518.086 \\
Sucrose & 100.000 \\
Fibre & 50.000 \\
Oil† & 70.000 \\
AIN-93G mineral mix $\ddagger$ & 35.000 \\
AlN-93G vitamin mix§ & 10.000 \\
Calcium carbonate & 12.500 \\
Choline chloride & 1.400 \\
tert-Butylhydroquinone & 0.014 \\
\hline
\end{tabular}

\footnotetext{
* American Institute of Nutrition (Reeves et al. 1993).

†Representing diets containing (per $\mathrm{kg}$ ): soyabean oil $70 \mathrm{~g}$ (SBO diet); soyabean oil $60 \mathrm{~g}+$ CLA $10 \mathrm{~g}$ (SBO+CLA diet); menhaden oil-safflower oil (56:44, w/w) $70 \mathrm{~g}$ (MSO diet); menhaden oil-safflower oil (56:44, w/w) $60 \mathrm{~g}+$ CLA $10 \mathrm{~g}$ (MSO + CLA diet). All four diets contained (per $\mathrm{kg}$ ): phylloquinone $750 \mu \mathrm{g}$, DL- $\alpha$-tocopheryl acetate $0.15 \mathrm{~g}$, blended with the oils.

$\ddagger$ Contained ( $/ \mathrm{kg})$ : ammonium metavanadate 0.00660 , ammonium molybdate 0.00795 , potassium iodate 0.01000 , sodium selenate 0.01025 , lithium chloride 0.01740 , sodium fluoride 0.06350 , nickel chloride 0.06370 , boric acid 0.08150 , chromium potassium sulfate 0.27500 , cupric car0.08150 , chromium potassium sulfate 0.27500 , cupric car-
bonate 0.30000 , manganous carbonate 0.63000 , sodium meta-silicate 1.08300 , zinc carbonate 1.65000 , ferric citrate 6.06000 , magnesium oxide 24.00000 , potassium sulfate 46.60000 , tri-potassium citrate 70.78000 , sodium chloride 74.00000 , potassium di-hydrogen phosphate 196.00000, sucrose 578.36110.

$\S$ Contained (per kg): DL- $\alpha$ tocopheryl acetate $15.000 \mathrm{~g}$, nicotinic acid $3.000 \mathrm{~g}$, cyanocobalamin $2.500 \mathrm{~g}$, calcium pantothenate $1.600 \mathrm{~g}$, retinyl palmitate $1.200 \mathrm{~g}$, cholecalciferol $1.000 \mathrm{~g}$, pyridoxine- $\mathrm{HCl} 700 \mathrm{mg}$, thiamine- $\mathrm{HCl} 600 \mathrm{mg}$, riboflavin $600 \mathrm{mg}$, folic acid $200 \mathrm{mg}$, D-biotin $20 \mathrm{mg}$ sucrose $973.580 \mathrm{~g}$.
}

nutrients for the growing rat as recommended by the American Institute of Nutrition (Reeves et al. 1993). A dietary level of $10 \mathrm{~g} \mathrm{CLA} / \mathrm{kg}$ diet was used in the present study, because this dietary level of CLA was shown to modulate bone formation in a previous study of young growing rats (Li et al. 1999). All diets were isoenergetic and isonitrogenous. Fresh diets were prepared every $14 \mathrm{~d}$ and kept at $-20^{\circ} \mathrm{C}$ until fed.

\section{Experimental design}

Forty male weanling rats, 28-d-old, Wistar strain (average weight $47.3 \mathrm{~g}$ ), obtained from the Biological Services Unit, University College, Cork, Republic of Ireland, were randomized by weight into four groups of ten rats each. The rats were assigned to four dietary groups (SBO, MSO, $\mathrm{SBO}+\mathrm{CLA}$ and MSO+CLA) following a $2 \times 2$ factorial design. Rats were housed individually, feed was provided ad libitum at 17.00 hours each day and all animals were given distilled water ad libitum for the duration of the study. Rats were weighed weekly and examined daily for general condition.

During the last week of the study, all rats were placed in individual metabolism cages with a grid-floor and a facility for separate collection of faeces and urine. To acclimatize the animals to the new environment, rats were placed in these cages $2 \mathrm{~d}$ before the beginning of a $4 \mathrm{~d}$ metabolic 
period for determination of net dietary $\mathrm{Ca}, \mathrm{Mg}$ and $\mathrm{P}$ absorption and urinary pyridinium crosslink excretion. Ad libitum intake of diets was measured during a $2 \mathrm{~d}$ period to determine average food intake per group. To assure complete and equivalent consumption of all food offered during the $4 \mathrm{~d}$ metabolic period, an equalized feeding paradigm was used. In the present study, the amount of food offered to all rats during the $4 \mathrm{~d}$ balance period was limited to $90 \%$ of the ad libitum food intake of the group that ate the least amount of food during the previous $2 \mathrm{~d}$. Feed was provided at 09.00 hours each day over the period and any remaining feed at 09.00 hours the following day was weighed. Quantitative collections of faeces were made over the $4 \mathrm{~d}$ period and these were pooled for each rat and stored at $-20^{\circ} \mathrm{C}$ until required for analysis.

During the metabolic period, urine samples $(24 \mathrm{~h})$ were collected for each animal in vessels that were covered with $\mathrm{Al}$ foil to prevent degradation of the pyridinium crosslinks by light. The urine samples for each animal were pooled and the volumes recorded. Portions of the pooled urine samples were acidified with $12 \mathrm{M}-\mathrm{HCl}(225 \mu \mathrm{l} /$ $100 \mathrm{ml}$ urine) and stored at $-20^{\circ} \mathrm{C}$ until required for analysis.

Net $\mathrm{Ca}, \mathrm{Mg}$ and $\mathrm{P}$ absorption were calculated as the difference between mineral intake from the diet and mineral recovered in the faeces during the $4 \mathrm{~d}$ period.

After $56 \mathrm{~d}$ on their respective diets, all animals were anaesthetized with diethyl ether and blood was drawn from the heart into vacutainer tubes, processed to serum and immediately stored at $-80^{\circ} \mathrm{C}$ until required. Final body weights were recorded, and femora and tibias were harvested and cleaned of adhering soft tissue. The distal epiphyses were removed from the left femora, and the metaphyseal-diaphyseal bone shafts were freed of bone marrow and blood. These were immediately placed in $\mathrm{Al}$ foil, then immersed in liquid $\mathrm{N}_{2}$ and were subsequently stored at $-80^{\circ} \mathrm{C}$ until required for mRNA analysis. The right femurs were dried overnight at $110^{\circ} \mathrm{C}$, weighed and stored in sealed containers until required for mineral analysis. The right tibia was prepared and processed for determination of ex vivo production of $\mathrm{PGE}_{2}$ (see later).

\section{Experimental techniques}

Urinary pyridinoline and deoxypyridinoline. Pooled urine samples were analysed in duplicate for urinary pyridinoline and deoxypyridinoline using a three-step procedure described by Doyle \& Cashman (2003).

Urinary creatinine levels. Urinary creatinine was measured in duplicate by a colorimetric procedure using a diagnostic kit (catalogue no. 555A; Sigma Diagnostics, St Louis, MO, USA). Intra- and inter-assay CV were 3.6 and $7.9 \%$ respectively.

Feed, faecal, femoral and urinary calcium, phosphorus and magnesium levels. Pooled (4 d) faecal samples from each animal were dried overnight at $110^{\circ} \mathrm{C}$ and mixed thoroughly. Femora and portions of dried faecal samples and the four diets were dry ashed at $600^{\circ} \mathrm{C}$ for $16 \mathrm{~h}$, as described by Hoshino et al. (1998), and the ash content was calculated by weight loss on a dry basis. The femoral, faecal and feed ash were solubilized with $1 \mathrm{M}-\mathrm{HNO}_{3}$ and
$\mathrm{Ca}$ and $\mathrm{Mg}$ were measured in duplicate in digests and in urine by atomic absorption spectrophotometry (Varian SpectrAA 600; JVA Analytical Ltd, Dublin, Republic of Ireland) after appropriate dilution with $\mathrm{LaCl}_{3}$ solution ( $5 \mathrm{~g} /$ 1; BDH Ltd, Poole, Dorset, UK). A range of Ca and Mg standards was used to obtain $\mathrm{Ca}$ and $\mathrm{Mg}$ calibration curves. The intra- and inter-assay CV for Ca were 2.8 and $7.8 \%$, and for $\mathrm{Mg}$ were 3.2 and $8.8 \%$ respectively. $\mathrm{P}$ was determined in the femoral, feed and faecal digests and urine by the method of Weissman \& Pileggi (1974). The intra- and inter-assay CV for $\mathrm{P}$ were 4.2 and $6.1 \%$ respectively. The accuracy of mineral analysis was assured in each analytical run by appropriate recovery of mineral in dry-ashed samples of National Institute of Standards and Technology-certified bone meal (standard reference material no. 1486; Laboratory of the Government Chemist, London, UK).

Femoral mass, length, volume and density. The length of each right femur was measured with a vernier caliper. Bone volume and density were measured by Archimedes' principle as described by Doyle \& Cashman (2003).

Serum osteocalcin and insulin-like growth factor-I levels. Serum osteocalcin concentrations were measured in duplicate using the Rat-Mid osteocalcin ELISA (Osteometer Biotech A/S, Osteopark, Herlev, Denmark). The intra- and inter-assay CV were 4.0 and $6.2 \%$ respectively. Serum IGF-I concentrations were measured in duplicate using a recently developed ELISA (Biomedical Technologies Inc., Stoughton, MA, USA). The intra- and inter-assay CV were 3.2 and $5.2 \%$ respectively.

Ex vivo production of prostaglandin $E_{2}$ by bone organ cultures. Ex vivo $\mathrm{PGE}_{2}$ production in bone organ cultures were performed as described by Watkins et al. (1996, 1997). In brief, shafts from the right tibia, once removed, were carefully flushed with a $0.15 \mathrm{M}-\mathrm{NaCl}$ solution to remove marrow cells. A weighed section of bone shaft was immersed in $20 \mathrm{ml}$ Hank's balanced salt solution (Sigma Chemical Co. Ltd) and incubated with shaking for $2 \mathrm{~h}$ at $37^{\circ} \mathrm{C}$. After incubation, the bone culture medium was collected and $\mathrm{PGE}_{2}$ concentrations measured in duplicate using a recently developed ELISA (Amersham Pharmacia Biotech UK Limited, Amersham, Bucks., UK). The intra- and inter-assay CV were 3.2 and $5.2 \%$ respectively. The protein concentration of the bone culture medium was determined by using the method of Lowry et al. (1951) and the $\mathrm{PGE}_{2}$ values were expressed as $\mathrm{ng}$ / $\mathrm{mg}$ protein.

Reverse transcription and quantitative polymerase chain reaction analysis for femoral insulin-like growth factor-I and osteocalcin mRNA. RNA was isolated and analysed in the left femora from each rat within a group $(n 8)$ as described by Fleet \& Hock (1994). Total RNA (1 $\mu \mathrm{g})$ from each rat was made into cDNA by the reverse transcription reaction described by Fleet \& Hock (1994). Primers sets for osteocalcin, IGF-I and glyceraldehyde phosphate dehydrogenase (GAPDH) were derived from previously published sequences (Fleet \& Hock, 1994). Quantitative polymerase chain reaction analysis of the samples was performed using the LightCycler system and software package for the analysis of fluorescent data (Roche-Diagnostics, Mannheim, Germany), as described by Witter et al. (1997). The dilution series of normal 
control cDNA served to provide a standard curve and allowed the quantification of the polymerase chain reaction-produced yield for all samples. Polymerase chain reaction mixtures contained $4 \mathrm{mM}-\mathrm{MgCl}_{2}$ and $0.5 \mu \mathrm{M}$ (IGF-I) or $1.0 \mu \mathrm{M}$ (osteocalcin, GAPDH) of each primer in $20 \mu \mathrm{l}$ volumes. Forty amplification cycles were performed, consisting of a denaturation step at $95^{\circ} \mathrm{C}$, annealing at $50^{\circ} \mathrm{C}$ (GAPDH), $58^{\circ} \mathrm{C}$ (osteocalcin) or $64^{\circ} \mathrm{C}$ (IGF-I), and an elongation step at $72^{\circ} \mathrm{C}$ for $8(\mathrm{GAPDH}), 12$ (osteocalcin) or 9 (IGF-I) s. A single fluorescence measurement was taken at the end of each elongation step. Identification of amplicons was performed by generation of a melting curve. The characteristic melting temperature for each amplicon was initially confirmed by agarose $(2 \%)$ gelethidium bromide electrophoresis with visualization on a u.v. transilluminator. All data for osteocalcin and IGF-I gene expression were normalized to the expression of GAPDH, a ubiquitously expressed housekeeping gene, in each animal.

\section{Statistical methods}

Data for all variables were normally distributed (as determined by the method of Kolmogorov and Smirnov) and were of equal variances (as determined by Bartlett's test) and thus allowed for parametric tests of significance. Results are presented as mean values with their pooled standard errors. Data were subjected to two-way ANOVA, with variation attributed to PUFA type and CLA (Snedecor \& Cochran, 1967). To follow up ANOVA, all pairs of mean values were compared by the method of least significant difference (Snedecor \& Cochran, 1967).

\section{Results}

Mean body-weight gain did not differ among groups (results not shown). The effects of CLA supplementation and dietary PUFA type on physical properties and macromineral content of femora are shown in Table 2. Femoral length, ash weight, proportion of ash and femoral density were unaffected by either dietary PUFA type or CLA supplementation. Femur dry weight and bone mineral mass tended to be lower $(P=0.075$ and $P=0.058$ respectively) in rats fed SBO (n-6 PUFA-rich diet) compared with those fed MSO (n-3 PUFA-rich diet), irrespective of CLA. There was no effect of dietary PUFA type or CLA supplementation on the concentration or content of femoral $\mathrm{Ca}, \mathrm{Mg}$ and $\mathrm{P}$ (Table 2).

Results for ex vivo $\mathrm{PGE}_{2}$ biosynthesis revealed that rats consuming SBO had a significantly higher $(P<0 \cdot 001)$ production of this prostanoid in bone organ culture compared with those given MSO, irrespective of CLA (Fig. 1). Addition of the CLA treatment to either the SBO or MSO diets lowered $(P<0 \cdot 05)$ ex vivo $\mathrm{PGE}_{2}$ production, dramatically so in rats receiving the SBO diet (Fig. 1).

The concentrations of IGF-I and osteocalcin in serum were unaffected by either dietary PUFA type or CLA supplementation (Table 3). Similarly, IGF-I and osteocalcin mRNA levels in femora were unaffected by either PUFA type or CLA supplementation (results not shown).

Urinary pyridinoline/creatinine and deoxypyridinoline/ creatinine levels were unaffected by CLA, irrespective of PUFA type (Table 3). Urinary pyridinoline/creatinine and deoxypyridinoline/creatinine were significantly $(P<0.05)$ higher in rats fed SBO compared with those fed MSO, irrespective of CLA (Table 3 ).

The effects of CLA supplementation and dietary PUFA type on food intake and $\mathrm{Ca}, \mathrm{Mg}$ and $\mathrm{P}$ absorption are shown in Table 4. PUFA type had no effect on food consumption over the $4 \mathrm{~d}$ balance period, irrespective of CLA. Food consumption by rats supplemented with CLA tended $(P=0.08)$ to be less than that of unsupplemented animals, irrespective of PUFA type. Net fractional (\%) and absolute $(\mathrm{mg}) \mathrm{Ca}$ absorption was significantly $(P<0.01$ and $P<0.05$ respectively) higher in CLA-supplemented than unsupplemented animals fed on the $n-3$ PUFA-rich diet, whereas CLA had no effect on fractional $\mathrm{Ca}$ absorption in animals fed the $n$-6 PUFA-rich diet. Net $\mathrm{Mg}$ absorption (either fractional or absolute) was

Table 2. Bone physical properties and mineral analysis of right femurs in young male rats fed different lipid treatments* (Mean values with their pooled standard errors for ten rats per group)

\begin{tabular}{|c|c|c|c|c|c|c|c|c|}
\hline \multirow{2}{*}{$\begin{array}{l}\text { PUFA type... } \\
\text { CLA supplementation... }\end{array}$} & \multicolumn{2}{|c|}{ SBO } & \multicolumn{2}{|c|}{ MSO } & \multirow[b]{2}{*}{ Pooled SEM } & \multicolumn{3}{|c|}{$\begin{array}{c}\text { Statistical significance of } \\
\text { variance ratio }(P) \text {, effects of: }\end{array}$} \\
\hline & - CLA & $+\mathrm{CLA}$ & - CLA & + CLA & & PUFA & CLA & PUFA $\times C L A$ \\
\hline \multicolumn{9}{|l|}{ Femur: } \\
\hline Length (mm) & $28 \cdot 13$ & $28 \cdot 23$ & $28 \cdot 21$ & 27.99 & 0.02 & 0.593 & 0.727 & 0.456 \\
\hline Dry wt (mg) & 363 & 366 & 375 & 378 & 8 & 0.075 & 0.705 & 0.949 \\
\hline Ash wt (mg) & 0.24 & 0.24 & 0.25 & 0.25 & 0.01 & 0.134 & 0.414 & 0.835 \\
\hline Density $\left(\mathrm{g} / \mathrm{mm}^{3}\right)^{\prime}$ & 0.00143 & 0.00140 & 0.00143 & 0.00139 & 0.00002 & 0.620 & 0.174 & 0.872 \\
\hline Bone mineral mass $(\mathrm{mg} / \mathrm{mm})$ & $8 \cdot 57$ & $8 \cdot 62$ & $8 \cdot 81$ & 9.05 & 0.17 & 0.058 & 0.422 & 0.581 \\
\hline $\mathrm{Ca}(\mathrm{mg} / \mathrm{g}$ dry $\mathrm{wt})$ & 274 & 283 & 294 & 281 & 9 & 0.391 & 0.848 & 0.118 \\
\hline $\mathrm{Mg}(\mathrm{mg} / \mathrm{g}$ dry wt) & $4 \cdot 23$ & $4 \cdot 39$ & $4 \cdot 20$ & $4 \cdot 29$ & 0.15 & 0.652 & 0.413 & 0.792 \\
\hline$P$ (mg/g dry wt) & 114 & 113 & 114 & 113 & 1 & 0.938 & 0.439 & 0.754 \\
\hline $\mathrm{Ca}$ (mg/bone) & 99 & 103 & 108 & 106 & 3 & 0.112 & 0.728 & 0.359 \\
\hline Mg (mg/bone) & 1.53 & 1.61 & 1.58 & 1.62 & 0.06 & 0.611 & 0.299 & 0.763 \\
\hline $\mathrm{P}$ (mg/bone) & 41.4 & $41 \cdot 3$ & $42 \cdot 8$ & $42 \cdot 8$ & 0.8 & 0.086 & 0.957 & 0.897 \\
\hline
\end{tabular}

PUFA, polyunsaturated fatty acid; SBO, soyabean oil; MSO, menhaden oil-safflower oil; CLA, conjugated linoleic acid.

${ }^{*}$ For details of diets and procedures, see Table 1 and p. 744. 


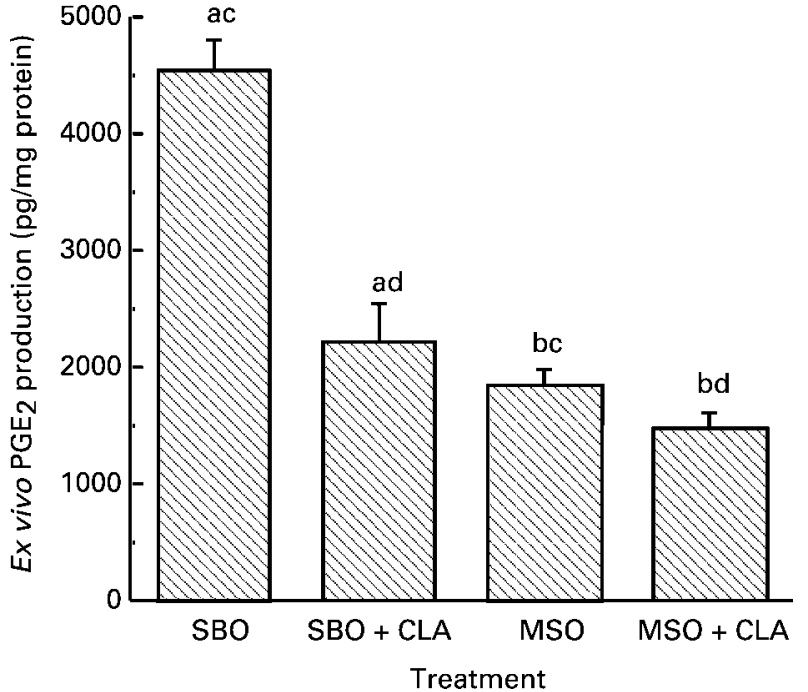

Fig. 1. Ex vivo prostaglandin $(P G) E_{2}$ production in bone (tibia) organ culture in growing male rats fed different dietary lipid treatments. Treatments were: soyabean oil diet (SBO); soyabean oil+ conjugated linoleic acid diet (SBO+CLA); menhaden oil-safflower oil diet (MSO); menhaden oil-safflower oil+conjugated linoleic acid diet (MSO+CLA). For details of diets and procedures, see Table 1 and p. 744. Values are means with their standard errors shown by vertical bars for eight rats per group. ${ }^{a, b}$ Mean values with unlike superscript letters were significantly different for the effect of polyunsaturated fatty acid (two-way ANOVA, $P<0.001$ ). ${ }^{\mathrm{c}, \mathrm{d}}$ Mean values with unlike superscript letters were significantly different for the effect of CLA (two-way ANOVA, $P<0.05$ ).

unaffected by PUFA type or CLA supplementation. Similarly, net absolute $\mathrm{P}$ absorption was unaffected by PUFA type or CLA supplementation.

\section{Discussion}

The findings of the present study suggest that while CLA had no effect on net absolute $\mathrm{Mg}$ and $\mathrm{P}$ absorption, it may enhance $\mathrm{Ca}$ absorption in rats fed a diet rich in $n-3$ PUFA. This stimulatory effect of CLA on Ca absorption was not observed in rats fed a diet rich in n-6 PUFA. This is the first study, to our knowledge, that has investigated the effect of CLA on $\mathrm{Ca}$ absorption in vivo. This stimulatory effect of CLA on Ca absorption in vivo, however, supports the findings from recent in vitro studies that showed that specific isomers of CLA significantly increased paracellular $\mathrm{Ca}$ transport in Caco-2 cells (Jewell \& Cashman, 2003a,b). Paracellular Ca transport is generally thought to be the predominant route of intestinal $\mathrm{Ca}$ absorption in vivo when $\mathrm{Ca}$ intake is adequate to high (Bronner, 1998). The mechanism by which CLA enhanced $\mathrm{Ca}$ absorption is unclear. Roche et al. (2001b) suggested that the effect of CLA on paracellular epithelial permeability might arise due to an alteration in the cellular distribution of occludin (an integral structural protein component of the tight junction between neighbouring intestinal cells). It is also unclear as to why CLA only promoted $\mathrm{Ca}$ absorption in a diet rich in $n-3$ and not $n-6$ PUFA. IGF-I, an important paracrine and autocrine regulatory polypeptide of many cells, is believed to play a role in intestinal Ca absorption (Fleet et al. 1994; Fatayerji et al. 2000). While circulating IGF-I levels were unaffected by either PUFA or CLA in the present study, IGF-binding protein-3 (although not measured) may have been differentially modulated by an interaction between CLA and n-3 and/or n-6 PUFA. For example, Li et al. (1999) found that CLA supplementation increased serum IGF-binding protein-3 levels in rats given a diet high in $n-6$ PUFA, but decreased it in rats fed a diet high in n-3 PUFA. A reduction in IGF-binding protein-3 in the $n$-3 PUFA+ CLA-supplemented rats may have increased the biological activity of IGF-I and in that way may have increased $\mathrm{Ca}$ absorption.

The additional $\mathrm{Ca}$ absorbed by CLA-supplemented rats fed on an $n$-3 PUFA-rich diet would be of little value unless it was retained by these animals. Unfortunately, the retention of $\mathrm{Ca}$ could not be estimated in the present study, because of contamination of urine samples with spilt food. However, fish oil, rich in $n-3$ fatty acids, has been shown to decrease urinary $\mathrm{Ca}$ excretion in animals by a down-regulation of $\mathrm{PGE}_{2}$ (Buck et al. 1991; Claassen et al. 1995a). Therefore, it is unlikely that the additional Ca absorbed by rats fed the diet rich in $n-3$ fatty acids and supplemented with CLA was excreted in urine. Rather, Ca retention may have been improved by the CLA-induced down-regulation of $\mathrm{PGE}_{2}$ levels in these MSO+CLA-fed rats, relative to those receiving the unsupplemented MSO. However, this would need to be confirmed,

Table 3. The effect of different lipid treatments on urinary pyridinoline (Pyr) and deoxypyridinoline (Dpyr) concentrations and serum osteocalcin and insulin-like growth factor (IGF)-I in young male rats*

(Mean values with their pooled standard errors for ten rats per group)

\begin{tabular}{|c|c|c|c|c|c|c|c|c|}
\hline \multirow{2}{*}{$\begin{array}{l}\text { PUFA type... } \\
\text { CLA supplementation... }\end{array}$} & \multicolumn{2}{|c|}{ SBO } & \multicolumn{2}{|c|}{ MSO } & \multirow[b]{2}{*}{ Pooled SEM } & \multicolumn{3}{|c|}{$\begin{array}{l}\text { Statistical significance of variance } \\
\text { ratio }(P) \text {, effects of: }\end{array}$} \\
\hline & - CLA & $+\mathrm{CLA}$ & - CLA & $+\mathrm{CLA}$ & & PUFA & CLA & $P U F A \times C L A$ \\
\hline \multicolumn{9}{|l|}{ Urine: } \\
\hline $\operatorname{Pyr}(\mathrm{nmol} / \mathrm{mmol} \mathrm{Cr})$ & 110 & 95 & 82 & 85 & 7 & 0.019 & 0.423 & 0.220 \\
\hline Dpyr (nmol/mmol Cr) & 194 & 176 & 155 & 153 & 13 & 0.036 & 0.450 & 0.581 \\
\hline \multicolumn{9}{|l|}{ Serum: } \\
\hline Osteocalcin (ng/ml) & $42 \cdot 6$ & $45 \cdot 4$ & $41 \cdot 2$ & $44 \cdot 3$ & 0.3 & 0.529 & 0.128 & 0.416 \\
\hline IGF-I (ng/ml) & 336 & 350 & 358 & 337 & 12 & 0.778 & 0.421 & 0.648 \\
\hline
\end{tabular}

PUFA, polyunsaturated fatty acid; SBO, soyabean oil; MSO, menhaden oil-safflower oil; CLA, conjugated linoleic acid; Cr, creatinine.

${ }^{*}$ For details of diets and procedures, see Table 1 and p. 744. 
Table 4. The effect of different lipid treatments on food intake and apparent absorption of calcium, phosphorus and magnesium in young male rats*

(Mean values with their pooled standard errors for ten rats per group)

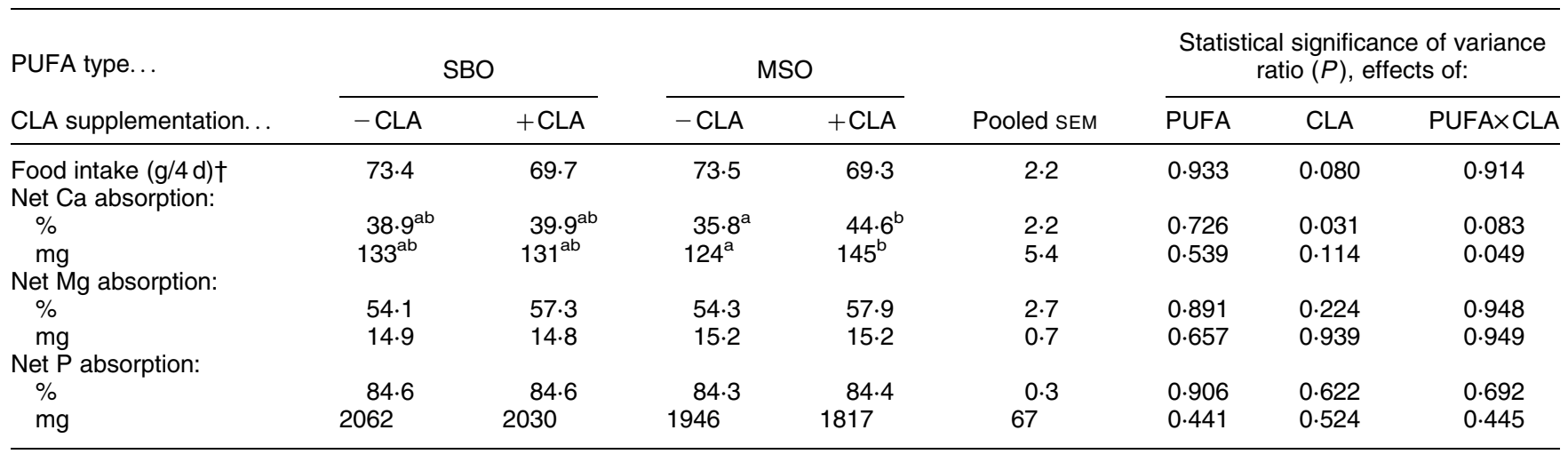

PUFA, polyunsaturated fatty acid; SBO, soyabean oil; MSO menhaden oil-safflower oil; CLA, conjugated linoleic acid.

${ }_{\mathrm{a}, \mathrm{b}}$ Mean values within a row with unlike superscript letters were significantly different (ANOVA followed by least significant difference test; $P<0.05$ ).

${ }^{*}$ For details of diets and procedures, see Table 1 and p. 744.

† Mean food consumption over the $4 \mathrm{~d}$ balance period (see p. 745 ).

especially as the increased $\mathrm{Ca}$ absorption in these rats was not translated into differences in bone mass or mineral content. Bone mass or mineral content were also unaffected by CLA supplementation of rats fed a diet high in $n-6$ PUFA. Therefore, while CLA supplementation did not appear to influence the physical properties or mineral content of bone over 8 weeks, Sinha et al. $(1988 a, b)$ has suggested that several months may be required to induce measurable changes in bone by dietary alteration.

There was a tendency for femoral dry weight and bone mineral mass to be lower in rats fed a diet high in $n-6$ fatty acids (SBO) compared with those fed a diet high in $n-3$ fatty acid (MSO). These findings are in agreement with those of Li et al. (1999), who reported similar findings in young growing male rats. The findings of both studies in young growing rats are also consistent with the results of a previous study that showed that chicks fed an $n-6$ PUFArich diet (SBO) for $21 \mathrm{~d}$ had reduced total bone and cortical bone areas in cross-sections of tibiae compared with chicks given menhaden oil (rich in $n$-3 PUFA) (Watkins et al. 1996). The reduced femoral dry weight and bone mineral mass in rats fed the $n-6$ PUFA-rich diet in the present study is consistent with the increased rate of bone resorption (as determined by the urinary pyridinium crosslinks, which are sensitive and specific markers; Black et al. 1989; Egger et al. 1994) in these animals, relative to the animals fed a diet rich in $n-3$ PUFA. In contrast, Claassen et al. (1995b) have shown that increasing the $n$-6 PUFA: $n$ 3 PUFA $(3: 1, w / w)$ reduced urinary pyridinium crosslink excretion in young growing male rats. The $n-6$ and $n-3$ PUFA used by Claassen et al. (1995b), however, were from evening primrose (Oenothera biennis) oil and fish oil respectively, whereas the $n-6$ and $n-3$ PUFA in the present study were from SBO and MSO respectively. Therefore, the particular bioactive fatty acids per se in these oils may be as important to bone health as the overall $n-6$ PUFA: $n-3$ PUFA ratio in the diet.

The mechanism by which the $n-3$ PUFA lowered the rate of bone resorption in the present study is unclear.
However, rats receiving a diet high in n-3 fatty acids (MSO) had significantly lower ex vivo $\mathrm{PGE}_{2}$ production in bone (tibia) organ culture compared with that in rats receiving a diet high in $n-6$ fatty acids (SBO). This finding is in close agreement with that of Li et al. (1999), who reported a similar response of ex vivo $\mathrm{PGE}_{2}$ production in rat tibia and femur to PUFA type. $\mathrm{PGE}_{2}$ is an important factor in the regulation of local bone metabolism, including bone resorption as well as bone formation (Raisz \& Fall, 1990; Marks \& Miller, 1993). Therefore, the $n$-3 PUFA may have lowered the rate of bone resorption as a consequence, at least in part, of their suppressive effect on $\mathrm{PGE}_{2}$ biosynthesis.

Addition of the CLA treatment to either diet further lowered ex vivo $\mathrm{PGE}_{2}$ production. Because CLA is incorporated into membrane phospholipids, it may compete with other PUFA in the formation of arachidonic acid (the precursor of $\mathrm{PGE}_{2}$ ) to inhibit $\mathrm{PGE}_{2}$ biosynthesis ( $\mathrm{Li} \&$ Watkins, 1998). However, while CLA further reduced the biosynthesis of $\mathrm{PGE}_{2}$, particularly in the $n-6$ PUFA-rich group, it had no effect on the rate of bone resorption in either dietary PUFA group.

As already mentioned, $\mathrm{PGE}_{2}$ is also an important regulatory factor in the rate of bone formation (Raisz \& Fall, 1990). For example, reduced production of $\mathrm{PGE}_{2}$ in chicks fed a diet high in $n-3$ PUFA was associated with an increased rate of bone formation (Xu et al. 1994; Watkins et al. 1996). However, in the present study as well as the study by Li et al. (1999), n-3 PUFA had no effect on the rate of bone formation in young growing rats, as assessed by serum osteocalcin (a biochemical marker of bone formation in rats (Creedon et al. 1999) used in both studies) or by histomorphometry (used by Li et al. 1999). Furthermore, while CLA reduced $\mathrm{PGE}_{2}$ biosynthesis in bone, it had no effect on serum osteocalcin in either study. Of note, Li et al. (1999) reported a reduced rate of mineral apposition and bone formation (measured by histomorphometry) in tibia of CLA-supplemented animals when compared with unsupplemented animals, 
irrespective of dietary PUFA type; the authors associated this with the inhibitory effect of CLA on ex vivo $\mathrm{PGE}_{2}$ production in bone of these rats. These findings might suggest that serum osteocalcin may lack sensitivity as a technique for detecting subtle dietary-induced changes in the rate of bone formation. However, femoral osteocalcin mRNA levels were also unaffected by CLA supplementation in the present study, suggesting no effect of CLA on osteocalcin synthesis at the transcriptional level.

$\mathrm{PGE}_{2}$ is known to be a potent regulator of IGF-I levels, at least in bone (McCarthy et al. 1991; Schmid et al. 1992). IGF-I is the most abundant growth factor in bone and is believed to function as both a systemic and local growth factor for bone tissue (Delany et al. 1994). In the present study, CLA had no effect on serum IGF-I levels in young growing rats, irrespective of PUFA type. This was despite the fact that CLA supplementation of these rats led to a reduction in $\mathrm{PGE}_{2}$ biosynthesis in bone. This is in contrast to the findings of $\mathrm{Li}$ et al. (1999), who showed that CLA reduced the circulating levels of IGF-I in growing rats. However, a reduction in $\mathrm{PGE}_{2}$ does not necessarily lead to a reduction in IGF-I levels. For example, in both the present study and that of $\mathrm{Li}$ et al. (1999), a diet high in $n$-3 PUFA had no effect on serum IGF-I in growing rats, despite markedly reducing ex vivo $\mathrm{PGE}_{2}$ production in bone, relative to that in rats fed a diet high in $n-6$ PUFA. There has also been some uncertainty as to whether changes in circulating concentrations of the IGF-I reflect local (bone tissue) concentrations, and the amount in bone tissue may be more important for bone formation (Rodan \& Rodan, 1995). However, in the present study, IGF-I mRNA levels in femora were unaffected by CLA supplementation; this is consistent with the serum findings.

In conclusion, there have been significant changes over the past few decades in the fat composition of the food supply, in agricultural methods of food preparation and in the eating habits of industrialized societies (Watkins et al. 2001). The present dietary $n-6: n-3$ fatty acids ratio may be far from the optimal recommended intake of $n-3$ fatty acids to protect against chronic disease risk (Simopoulos et al. 1999). The findings of the present study in young growing rats suggest that a diet high in $n-3$ fatty acids may be beneficial for bone metabolism and mass. Furthermore, $n-3$ fatty acids appeared to interact with CLA in promoting intestinal $\mathrm{Ca}$ absorption, which, if sustained, would also benefit bone in the longer term. The mechanisms of action of these effects by bioactive fatty acids require further investigation. The level of CLA used in the present study $(10 \mathrm{~g} / \mathrm{kg}$ diet), although higher than that found in conventional diets without supplementation, compares favourably with the range used in other animal studies $(5-15 \mathrm{~g} / \mathrm{kg})$ that examined anti-inflammatory and anti-carcinogenic properties of CLA (Ip et al. 1991, 1996; Chin et al. 1994) as well as effects on bone ( $\mathrm{Li}$ et al. 1999). However, further research is needed to evaluate more typical dietary levels (including levels achieved with consumption of CLA supplements, a practice that is gaining in popularity) on $\mathrm{Ca}$ and bone metabolism, preferably in studies with human subjects.

\section{Acknowledgement}

This work was supported by funding made available by the Irish Government under the National Development Plan 2000-2006.

\section{References}

Black D, Farquharson C \& Robins SP (1989) Excretion of pyridinium crosslinks of collagen in ovariectomized rats as urinary markers for increased bone resorption. Calcif Tissue Int 44, 343-347.

Bronner F (1998) Calcium absorption - a paradigm for mineral absorption. J Nutr 128, 917-920.

Buck AC, Davies RL \& Harrison T (1991) The protective role of eicosapentaenoic acid [EPA] in the pathogenesis of nephrolithiasis. J Urol 146, 188-194.

Cashman KD (2002) Calcium intake, calcium bioavailability and bone health. Br J Nutr 87, S169-S177.

Chin SF, Storkson JM, Liu W, Albright KJ \& Pariza MW (1994) Conjugated linoleic acid (9,11- and 10,12-octadecadienoic acid) is produced in conventional but not germ-free rats fed linoleic acid. $J$ Nutr 124, 694-701.

Claassen N, Coetzer H, Steinmann CM \& Kruger MC (1995a) The effect of different $n-6 / n-3$ essential fatty acid ratios on calcium balance and bone in rats. Prostaglandins Leukot Essent Fatty Acids 53, 13-19.

Claassen N, Potgieter HC, Seppa M, et al. (1995b) Supplemented gamma-linolenic acid and eicosapentaenoic acid influence bone status in young male rats: effects on free urinary collagen crosslinks, total urinary hydroxyproline, and bone calcium content. Bone 16, 385S-392S.

Cook ME, Jerome DL \& Pariza M (1997) Broilers fed conjugated linoleic acid had enhanced bone ash. Poult Sci 76, 162.

Creedon A, Flynn A \& Cashman K (1999) The effect of moderately and severely restricted dietary magnesium intakes on bone composition and bone metabolism in the rat. $\mathrm{Br} J$ Nutr 82, 63-71.

Delany AM, Pash JM \& Canalis E (1994) Cellular and clinical perspectives on skeletal insulin-like growth factor I. J Cell Biochem 55, 328-333.

Doyle L \& Cashman KD (2003) The effect of nutrient profiles of the Dietary Approaches to Stop Hypertension (DASH) diets on blood pressure and bone metabolism and composition in normotensive and hypertensive rats. Brit J Nutr 89, $713-724$.

Egger CD, Mühlbauer RC, Felix R, Delmas PD, Marks SC \& Fleisch H (1994) Evaluation of urinary pyridinium crosslink excretion as a marker of bone resorption in the rat. J Bone Miner Res 9, 1211-1219.

Fatayerji D, Mawer EB \& Eastell R (2000) The role of insulin-like growth factor I in age-related changes in calcium homeostasis in men. J Clin Endocrinol Metab 85, 4657-4662.

Fleet JC, Bruns ME, Hock JM \& Wood RJ (1994) Growth hormone and parathyroid hormone stimulate intestinal calcium absorption in aged female rats. Endocrinology 134, 1755-1760.

Fleet JC \& Hock JM (1994) Identification of osteocalcin mRNA in nonosteoid tissue of rats and humans by reverse transcription-polymerase chain reaction. $J$ Bone Miner Res 9, $1565-1573$

Fleet JC \& Wood RJ (1999) Specific 1,25(OH) ${ }_{2} \mathrm{D}_{3}$-mediated regulation of transcellular calcium transport in caco- 2 cells. Am J Physiol 276, G958-G964.

Ip C, Briggs SP, Haegele AD, Thompson HJ, Storkson J \& Scimeca JA (1996) The efficacy of conjugated linoleic acid in mammary cancer prevention is independent of the level or type of fat in the diet. Carcinogenesis 17, 1045-1050. 
Ip C, Chin SF, Scimeca JA \& Pariza MW (1991) Mammary cancer prevention by conjugated dienoic derivative of linoleic acid. Cancer Res 51, 6118-6124.

Hoshino H, Kushida K, Takahashi M, Koyama S, Yamauchi H \& Inoue T (1998) Effects of low phosphate intake on bone and mineral metabolism in rats: evaluation by biochemical markers and pyridinium cross-link formation in bone. Ann Nutr Metab 42, 110-118.

Jewell C \& Cashman KD (2003a) The effect of conjugated linoleic acid and medium-chain fatty acids on transepithelial calcium transport in human intestinal-like Caco-2 cells. $\mathrm{Br} J$ Nutr 89, 639-647.

Jewell C \& Cashman KD (2003b) Effect of medium chain fatty acids on Caco-2 cell transepithelial calcium transport. Proc Nutr Soc (In the Press).

Kritchevsky D (2000) Antimutagenic and some other effects of conjugated linoleic acid. Brit J Nutr 83, 459-465.

Kruger MC, Coetzer H, de Winter R, Gericke G \& van Papendorp DH (1998) Calcium, gamma-linolenic acid and eicosapentaenoic acid supplementation in senile osteoporosis. Aging (Milano) 10, 385-394.

Kruger MC \& Horrobin DF (1997) Calcium metabolism, osteoporosis and essential fatty acids: a review. Prog Lipid Res 36, 131-151.

Li Y, Seifert MF, Ney DM, et al. (1999) Dietary conjugated linoleic acids alter serum IGF-1 and IGF binding protein concentrations and reduce bone formation in rats fed $(n-6)$ or (n-3) fatty acids. J Bone Miner Res 14, 1153-1162.

Li Y \& Watkins BA (1998) Conjugated linoleic acids alter bone fatty acid composition and reduce ex vivo prostaglandin $E_{2}$ biosynthesis in rats fed $n-6$ or $n-3$ fatty acids. Lipids 33, 417-425.

Lowry OH, Rosebrough NJ, Farr AL \& Randall RJ (1951) Protein measurement with the Folin phenol reagent. J Biol Chem 193, 265-275.

McCarthy TL, Centrella M, Raisz LG \& Canalis E (1991) Prostaglandin $\mathrm{E}_{2}$ stimulates insulin-like growth factor I synthesis in osteoblast-enriched cultures from fetal rat bone. Endocrinology 128, 2895-2900.

Marks SC \& Miller SC (1993) Prostaglandins and the skeleton: the legacy and challenges of two decades of research. Endocr J 1, 337-344.

Park P, Albright KJ, Liu W, Storkson JM, Cook ME \& Pariza MW (1997) Effect of conjugated linoleic acid on body composition in mice. Lipids 32, 853-858.

Raisz LG \& Fall PM (1990) Biphasic effects of prostaglandin $E_{2}$ on bone formation in cultured fetal rat calvariae: interaction with cortisol. Endocrinology 126, 1654-1659.

Reeves PG, Nielsen FH \& Fahey GC Jr (1993) AIN-93 purified diets for laboratory rodents: final report of the American Institute of Nutrition Ad Hoc Writing Committee on the reformulation of the AIN-76A rodent diet. J Nutr 123, 1939-1951.
Roche HM, Noone E, Nugent A \& Gibney MJ (2001a) Conjugated linoleic acid: a novel therapeutic nutrient? Nutr Res Rev 14, $173-187$.

Roche HM, Terres AM, Black IB, Gibney MJ \& Kelleher D (2001b) Fatty acids and epithelial permeability: effect of conjugated linoleic acid in Caco-2 cells. Gut 48, 797-802.

Rodan GA \& Rodan SB (1995) The cells of bone. In Osteoporosis: Etiology, Diagnosis, and Management, 2nd ed., pp. 1-39 [BL Riggs and LJ Melton III, editors]. Philadelphia, PA: Lippincot-Raven.

Schmid C, Schläpfer I, Waldvogel M, Zapf J \& Froesch ER (1992) Prostaglandin $E_{2}$ stimulates synthesis of insulin-like growth factor binding protein-3 in rat bone cells in vitro. J Bone Miner Res 7, 1157-1163.

Simopoulos AP, Leaf A \& Salem N Jr (1999) Essentiality of and recommended dietary intakes for omega- 6 and omega-3 fatty acids. Ann Nutr Metab 43, 127-130.

Sinha R, Smith JC Jr \& Soares JH Jr (1988a) Calcium and vitamin $\mathrm{D}$ in bone metabolism: analyses of their effects with a short-term in vivo bone model in rats. $J$ Nutr 118, 99-106.

Sinha R, Smith JC Jr \& Soares JH Jr (1988b) The effect of dietary calcium on bone metabolism in young and aged female rats using a short-term in vivo model. J Nutr 118, $1217-1222$.

Snedecor GW \& Cochran WG (1967) Statistical Methods. Ames, IA: Iowa State University Press.

van Dokkum W, Cloughley FA, Hulshof KF \& Oosterveen LA (1983) Effect of variations in fat and linoleic acid intake on the calcium, magnesium and iron balance of young men. Ann Nutr Metab 27, 361-369.

Watkins BA, Li Y, Lippman HE \& Seifert MF (2001) Omega-3 polyunsaturated fatty acids and skeletal health. Exp Biol Med 226, 485-497.

Watkins BA, Shen CL, Allen KG \& Seifert MF (1996) Dietary (n-3) and $(n-6)$ polyunsaturates and acetylsalicylic acid alter ex vivo $\mathrm{PGE}_{2}$ biosynthesis, tissue IGF-1 levels, and bone morphometry in chicks. J Bone Miner Res 11, 1321-1332.

Watkins BA, Shen CL, McMurtry JP, et al. (1997) Dietary lipids modulate bone prostaglandin $\mathrm{E}_{2}$ production, insulin-like growth factor-1 concentration and formation rate in chicks. $J$ Nutr $\mathbf{1 2 7}$, 1084-1091.

Weissman N \& Pileggi VJ (1974) Inorganic ions. In Clinical Chemistry: Principals and Techniques, pp. 639-755 [RJ Henry, DC Cannon and JW Winkelman, editors]. Hagerstown, MD: Harper and Row.

Witter CT, Ririe KM, Andrew RV, David DA, Gundry R \& Balis UJ (1997) The LightCycler ${ }^{\mathrm{TM}}$ : a microvolume multisample fluorimeter with rapid temperature control. Biotechniques 22, $176-181$.

Xu H, Watkins BA \& Adkisson HD (1994) Dietary lipids modify the fatty acid composition of cartilage, isolated chondrocytes and matrix vesicles. Lipids 29, 619-625. 